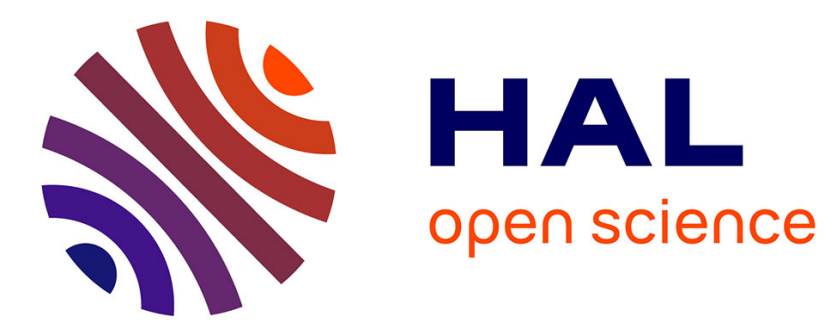

\title{
Laparoscopic partial alpps: much better than alpps!
} Stéphanie Truant, Mehdi El Amrani, Clio Baillet, Anne Ploquin, Katia Lecolle, Olivier Ernst, Mohamed Hebbar, Damien Huglo, Francois-Rene Pruvot

\section{- To cite this version:}

Stéphanie Truant, Mehdi El Amrani, Clio Baillet, Anne Ploquin, Katia Lecolle, et al.. Laparoscopic partial alpps: much better than alpps!. Annals of hepatology: official journal of the Mexican Association of Hepatology, 2019, 18 (1), pp.269-273. 10.5604/01.3001.0012.7937 . hal-03265599

\section{HAL Id: hal-03265599 \\ https://hal.univ-lille.fr/hal-03265599}

Submitted on 21 Jun 2021

HAL is a multi-disciplinary open access archive for the deposit and dissemination of scientific research documents, whether they are published or not. The documents may come from teaching and research institutions in France or abroad, or from public or private research centers.
L'archive ouverte pluridisciplinaire HAL, est destinée au dépôt et à la diffusion de documents scientifiques de niveau recherche, publiés ou non, émanant des établissements d'enseignement et de recherche français ou étrangers, des laboratoires publics ou privés.

\section{(1) (1) $\$$}

Distributed under a Creative Commons Attribution - NonCommercial - NoDerivatives| 4.0 


\title{
Laparoscopic Partial ALPPS: Much Better Than ALPPS!
}

\author{
Stéphanie Truant, ${ }^{*}$ Mehdi El Amrani, ${ }^{*}$ Clio Baillet, ${ }^{* *}$ Anne Ploquin, ${ }^{* * *}$ \\ Katia Lecolle, ${ }^{\star}$ Olivier Ernst, ${ }^{\star \star \star \star}$ Mohamed Hebbar, ${ }^{* \star}$ Damien Huglo, ${ }^{* *}$ François-René Pruvot ${ }^{\star}$ \\ * Department of Digestive Surgery and Transplantation, Huriez Hospital, University of Lille, France. \\ ** Department of Nuclear Medicine, Huriez Hospital, University of Lille, France. \\ *** Department of Medical Oncology, Huriez Hospital, University of Lille, France. \\ **** Department of Radiology, Huriez Hospital, University of Lille, France.
}

\section{ABSTRACT}

Associating Liver Partition and Portal Vein Ligation for Staged Hepatectomy (ALPPS) has emerged as an alternative for patients with bilobar colorectal liver metastasis deemed unresectable due to inadequate future remnant liver (FRL). Nevertheless, high morbidity and mortality rates have been reported. In this setting, including hepatobiliary scintigraphy in the clinical and surgical management of patients offered ALPPS has been advocated to both assess eligibility for ALPPS stage1 and suitable time for ALPPS stage2. Recently, it was stated that partial ALPPS with a liver split restricted to $50 \%$ of the transection line (or up to the middle hepatic vein in case of right extended hepatectomy) and a shortened stage 1 allows improving the postoperative course without precluding the inter-stages FRL hypertrophy. We describe a case series of p-ALPPS with stage 1 performed laparoscopically, including sequential assessments of the FRL volumes and functions via pre-stage 1 and pre-stage2 computed tomography volumetry and HIDA SPECT-scintigraphy. In five patients, laparoscopic p-ALPPS was associated with rapid and significant gain of remnant functional volume - much better than previously observed for ALPPS - facilitating early stage2 without inflammatory adherences. In conclusion, laparoscopic p-ALPPS is feasible and seems less aggressive than the original ALPPS technique with total transection. It may be an interesting alternative to the classical portal vein embolization (PVE) and two-stage hepatectomy strategy.

Key words. Liver. Cancer. Surgery. Regeneration. Scintigraphy.

\section{INTRODUCTION}

In a recent pilot study, ${ }^{1}$ we first warned surgeons about the drop in total liver function in the inter-stages period of the newly-developed ALPPS technique, which was in direct connection with the reportedly-high morbi-mortality rates reaching up to $13 \%{ }^{2}$ This was due to a loss of function in the excluded liver that was sharper than the function gain in the future remnant liver (FRL); this latter that was $+12.5 \%$ in average $[4.2 \%-28.6 \%]$ was further delayed and lower than the FRL volumetric gain (+42.6\% [18.3\%-110.2\%]). Despite the "auxiliary liver" role of the excluded segments, this resulted in some degree of liver failure in the inter-stages that exposed patients to fatale liver failure following the second stage of ALPPS, especially those with complicated inter-stages in agreement with literature data. ${ }^{2,3}$ The main hypotheses for this phenomenon were:

- The occurrence of severe complications in the surgical site, mainly biliary fistula and/or infected peritoneal fluid, that could hinder the FRL from regenerating. ${ }^{2}$

- The proliferation of enlarged hepatocytes that are increased in size (explaining the FRL volume gain) but also immature and nonfunctional at the beginning of hepatocellular regeneration. ${ }^{4}$

All of these data have just been confirmed in a large multicentric study including 27 patients with systematic sequential scintigraphy (before stage 1 and stage 2$){ }^{5}$

Recently, the high morbi-mortality rates of the original ALPPS technique have been significantly reduced thanks 
to better patient selection and many technical improvements. ${ }^{6,7}$ The main progress has come from the partial ALPPS (p-ALPPS) technique that limits the deleterious congestion of the excluded segments and the segment IV necrosis by preserving their outflow via the middle hepatic vein, improving the postoperative outcome while achieving similar FRL rapid hypertrophy. Following such innovations and pursuing sequential scintigraphy (prestage 1 and pre-stage2) in our ALPPS patients, we wondered whether these technical improvements were also associated with an improved functional gain of the FRL in the inter-stages of ALPPS.

\section{CASE SERIES}

Five patients with colorectal liver metastases and a FRL volume deemed insufficient before a right extended hepatectomy had a p-ALPPS through a laparoscopic approach and standardized technique, consisting in:

- Intraoperative ligation of the right portal vein branch dissected electively (avoiding dissection of the remaining structures of the pedicle).

- Partial liver split along the umbilical fissure preserving the middle hepatic vein just upstream its confluence with the left hepatic vein.

The p-ALPPS was performed upfront in 3 and as a rescue procedure after failed PVE in two at the discre- tion of the surgeon (Table 1). Three patients had undergone previous right colectomy for primary tumor by laparotomy $(n=2)$ or laparoscopy. Stage1 could be performed laparoscopically in all cases, requiring in average 3 to 4 trocars to carry out - after a systematic intraoperative ultrasonography-the primary control and division of the right portal vein followed by parenchymal transection up to the middle hepatic vein using ultrasonic dissector; mobilization of the right liver was not done in order to minimize the first stage impact according to the concept of the mini-ALPPS technique, ${ }^{8}$ resulting in a short operative duration of $270 \mathrm{~min}$ [185395] and low blood losses of 250cc [100-500] (Table 1). In the inter-stages, no patients showed any surgical complication, in particular no bilious and/or infected peritoneal fluid was observed at laparotomy for stage2, and none met the ISGLS criteria of liver failure or MELD score above 10 - all of these factors being reportedly particularly worrying after stage 1 as associated with a high risk of post-stage 2 liver failure. ${ }^{2,3}$ Scintigraphy reevaluations after stage 1 were carried out as previously reported ${ }^{4}$ on postoperative day (POD) 5 or 6 in all patients but one (POD12) who had partial liver split deemed less satisfactory due to severe post-colectomy adherences precluding transection up to the middle hepatic vein. We decided upfront to delay stage 2 at POD14 for this latter patient who was thus discharged on POD5 after stage1. Contrasting with the above-mentioned weak functional gain of the original ALPPS tech-

Table 1. Main patients' characteristics and perioperative data.

Age (years)

Gender (Male / Female)

Preoperative chemotherapy

Number of cycles

Pre-ALPPS PVE

Number of resected segments

FRL volume to body weight ratio

$\mathrm{FRL}$ volume increase

$F R L$ function increase

Perioperative data Operative duration (min)

Blood losses $(\mathrm{mL})$

Duration of hospitalization

Cumulated for both stages

Complication (n patients)

Major (Clavien $\geq 3 a$ ) *

Liver failure (ISGLS)

Death
$60.8[49.2-68.3]$

$3 / 2$

$100 \%$

10 [5-16]

2

$5[5-6]$

$0.4(0,29-0.5)$

$+60 \%[+18.6 \%$ to $+108.1 \%]$

$+47 \%[+37 \%$ to $+64 \%]$

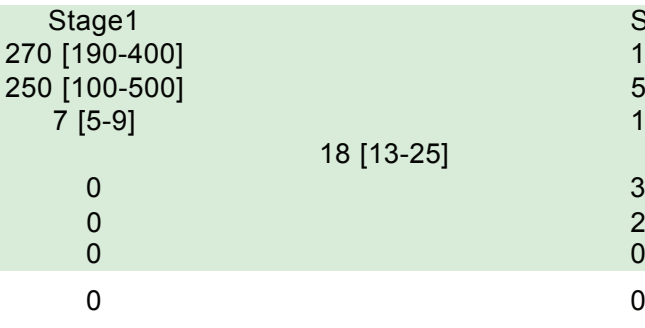

Stage 2

188 [150-260]

$550[100-1400]$

11 [6-18]

3
2
0
0

Results are expressed as median [Ranges]. PVE: portal vein embolization. FRL: future remnant liver. Rate changes of liver hepatic volume and function of the FRL were calculated as follows: (postoperative X-preoperative X)/preoperative X. Major complications after ALPPS stage 2 consisted in two patients in an abdominal collection requiring a percutaneous drainage, showing biliary fistula in one but only sterile ascites in the other patient. 

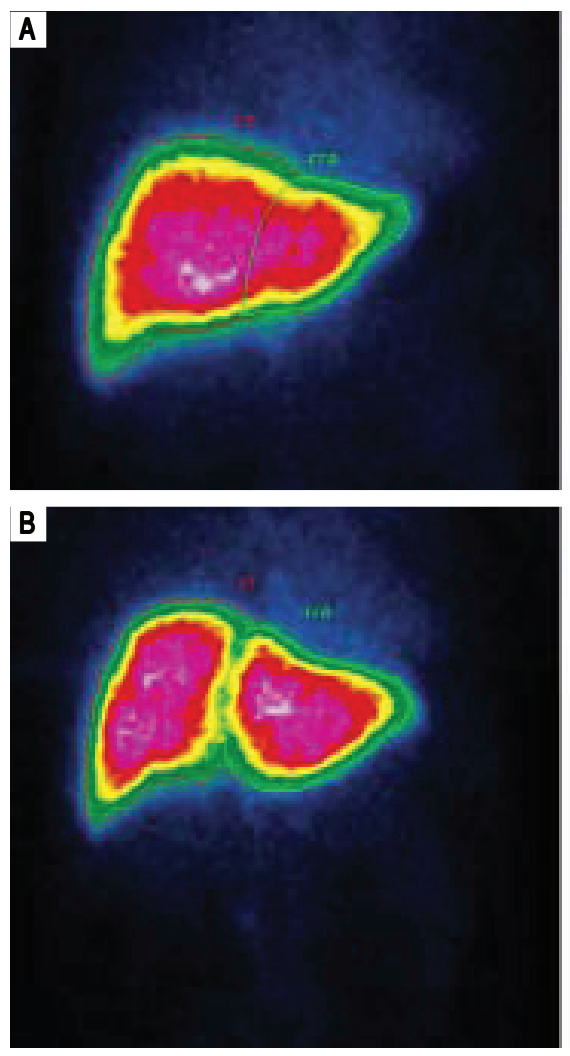

Figure 1. (A) Pre-stage1 and (B) post-stage1 (POD5) scintigraphy in one patient scheduled for a right extended hepatectomy who underwent a laparoscopic partial ALPPS along the umbilical fissure up to the middle hepatic vein, showing a functional gain of the FRL (left lobe) of $+44 \%$.

nique with total transection, these 5 p-ALPPS patients showed a marked FRL functional gain ranging between $+37 \%$ and $+64 \%$ (median of $+47 \%$; Figure 1 ). These significant FRL functional gains were not so far from the increase in FRL volume (median of $+60 \%$; ranges: $+18.6 \%$ to $+108.1 \%$ ), allowing performing the ALPPS stage 2 early on POD 6 to 7 in all patients except the above-mentioned patient who had postponing of stage 2 onPOD13. For the latter, the volume gain was $+18.6 \%$ only on POD13, but with a functional gain of $+63.6 \%$ allowing stage 2 . In all cases, the stage 2 that was done by laparotomy was facilitated by the absence of severe adhesions thanks to the laparoscopic approach for stage1 (Figure 2). Also contrasting with the original ALPPS technique, there was no necrosis of the segment IV despite complete interruption of its afferent vascular pedicles. The median stage 2 operative duration was 190min [153-259] and blood losses 550cc [100-1400]. Following stage2, 2 patients showed a Clavien grade III complication (percutaneous drainage for biliary fistula and for suspicion of subphrenic biloma that was in fact sterile ascites in one patient each), while another showed biliary fistula by surgical drain with spontaneous healing. There was no liver failure or death despite a FRL function as low as $1.8 \% / \mathrm{min} / \mathrm{m}^{2}$ in $2 \mathrm{p}$-ALPPS patients, far below the cutoff of $2.7 \% / \mathrm{min} / \mathrm{m}^{2}$ advocated by the Amsterdam's team ${ }^{9}$ as the minimum functional FRL tolerable for major liver resection but with so far no clear cut-off for ALPPS(5); these 2 patients displayed significant inter-stages function gain $(>50 \%)$ prompting us to maintain early stage 2 . The overall median total hospitalization time was 18 [13-25] days (7 [5-9] days for stage 1 and 11 [6-18] days for stage2; Table 1).

\section{DISCUSSION}

Overall, this was the first time that we observed such high rates of functional gain in the inter-stages of ALPPS procedures improved as p-ALPPS with stage 1 done laparoscopically. Moreover these functional gains were extremely rapid as occurring as soon as POD5 in most patients, allowing performing the stage 2 on POD 6 or 7 in these cases. The main hypotheses for this beneficial effect of p-ALPPS are the low rate of inter-stages local and systemic complications thanks to a less aggressive stage 1 according to the concept of "mini-ALPPS" technique $^{8}$ and to preservation of the excluded segments outflow avoiding the deleterious necrosis of the segment IV and presumably a decreased cytokines and inflammatory storm. This may be especially true when the stage1 can be done during a short standardized laparoscopic procedure; by magnifying the operative view, the laparoscopic 

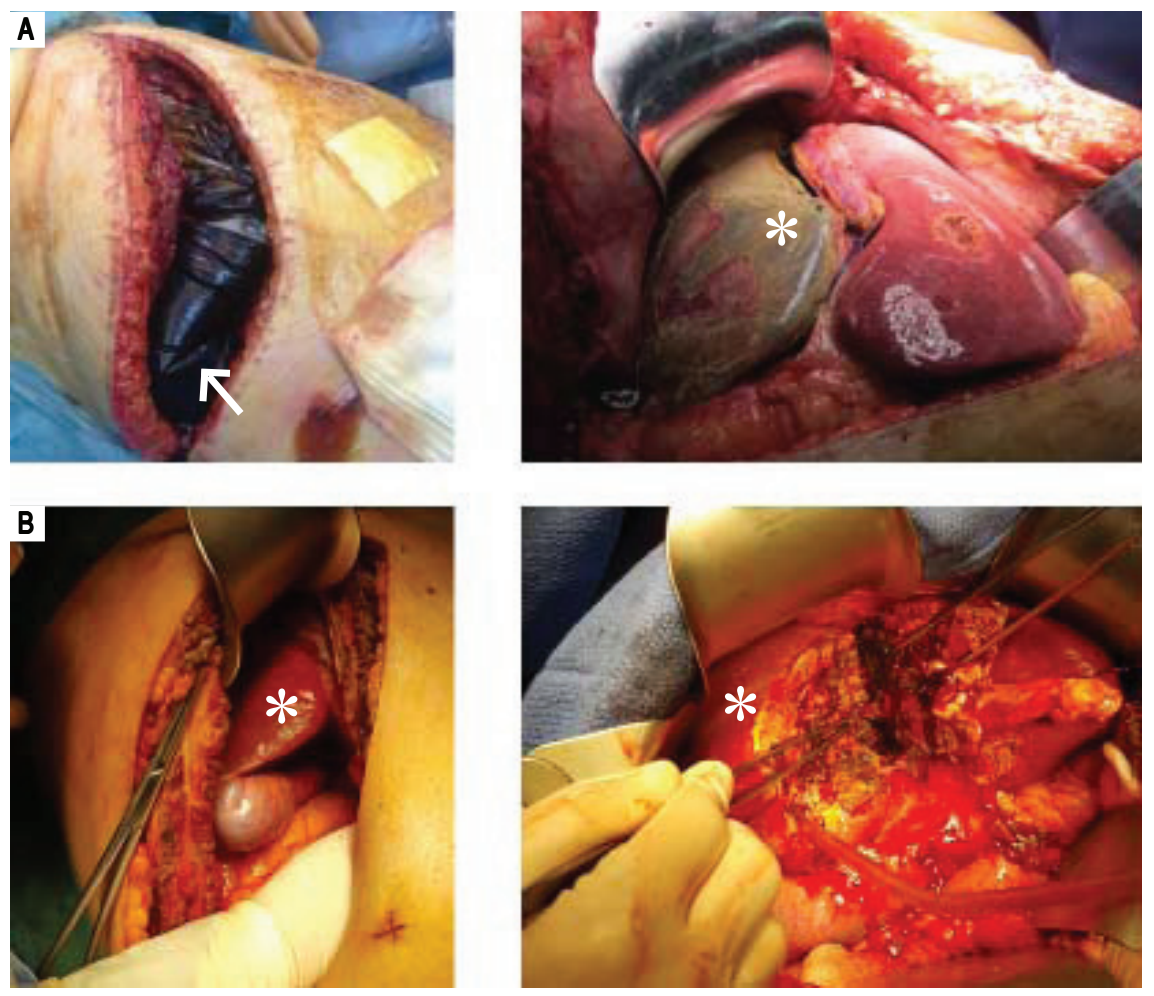

Figure 2. Laparotomy for stage2 of ALPPS along the umbilical fissure (A) with total parenchymal transection at the onset of ALPPS technique, showing bilious fluid within the perihepatic plastic bag (white arrow) and necrosis of the segment IV (white asterix) (B) by partial ALPPS performed laparoscopically, with no peritoneal fluid at laparotomy on POD6, no adhesion, and no necrosis of the segment IV (white asterix) despite interruption of its afferent pedicles.

approach allowed a direct dissection to the right portal vein branch and its elective ligation (with "no touch" to the remnant pedicle); the appearance of inter-stages adhesions was limited by the laparoscopic approach itself but also by the offered possibility to perform stage 2 early as a result of substantial functional gain. The main difficulty came from the challenging partial liver split along the umbilical fissure entailing a risk for iatrogenic lesion to the bile ducts of the segments II-III or IV (as previously-described for the original ALPPS technique), though potentially reduced thanks to laparoscopic magnification; moreover the avoidance of segment IV necrosis decreased the incidence of biliary leak or infected abdominal fluid. Overall, this standardized laparoscopic approach for the first step is certainly a good option for colorectal metastases indication, but it may also have an increasing role in the treatment of hepatocellular carcinoma. ${ }^{10}$ The choice for a laparoscopic approach with portal vein branch ligation and limited transection, leading to a less morbid stage1, may also open the concept and key-research of a new equilibrium between inflammatory and growth factors enhancing or limiting liver regeneration. These data have now to be confirmed in larger series of modified ALPPS procedures, as well as the potential oncological benefit of these less complicated procedures with probably lower immunosuppressive effect. In the future, the respective role of p-ALPPS $v$.
PVE (or double embolization of the ipsilateral portal and hepatic vein) in patients scheduled for extended hepatectomy will have to be determined.

\section{ABBREVIATIONS}

- ALPPS: Associating Liver Partition and Portal Vein Ligation for Staged Hepatectomy.

- FRL: future remnant liver.

- p-ALPPS: partial ALPPS.

- POD: postoperative day.

- PVE: portal vein embolization.

- SPECT: single photon emission computed tomography.

\section{CONFLICT OF INTEREST}

The authors declares that there is no conflict of interest regarding the publication of this article.

\section{AUTHORS' CONTRIBUTION}

Conception and design: Truant S, Baillet C, Lecolle K. Analysis and interpretation: Baillet C, Huglo D, Ernst O. Data collection: Lecolle K, El Amrani M, Ploquin A, Ernst O. Writing the article: Truant S, Ploquin A, Pruvot FR. Critical revision of the article and obtaining funding: Pruvot FR, Hebbar M. 


\section{FINANCIAL DISCLOSURES}

None.

\section{REFERENCES}

1. Truant S, Baillet C, Deshorgue AC, Leteurtre E, Hebbar M, Ernst O, Huglo D, et al. Drop of Total Liver Function in the Interstages of the New Associating Liver Partition and Portal Vein Ligation for Staged Hepatectomy Technique: Analysis of the Auxiliary Liver by HIDA Scintigraphy. Ann Surg 2016; 263: e33-4.

2. Truant S, Scatton O, Dokmak S, Regimbeau JM, Lucidi V, Laurent A, Gauzolino R, et al. Associating liver partition and portal vein ligation for staged hepatectomy (ALPPS): Impact of the inter-stages course on morbi-mortality and implications for management. Eur J Surg Oncol 2015; 41: 674-82.

3. Schadde E, Raptis DA, Schnitzbauer AA, Ardiles V, Tschuor C, Lesurtel M, Abdalla EK, et al. Prediction of Mortality After ALPPS Stage-1: An Analysis of 320 Patients From the International ALPPS Registry. Ann Surg 2015; 262: 780-6.

4. Truant S, Baillet C, Deshorgue AC, El Amrani M, Huglo D, Pruvot F-R. Contribution of hepatobiliary scintigraphy in assessing ALPPS most suited timing. Updates Surg 2017; 69: 411-9.

5. Olthof PB, Tomassini F, Huespe PE, Truant S, Pruvot F-R, Troisi RI, Castro C, et al. Hepatobiliary scintigraphy to evaluate liver function in associating liver partition and portal vein ligation for staged hepatectomy: Liver volume overestimates liver function. Surgery 2017; 162: 775-83.
6. Schadde E, Ardiles V, Robles-Campos R, Malago M, Machado M, Hernandez-Alejandro R, Soubrane O, et al. Early survival and safety of ALPPS: first report of the International ALPPS Registry. Ann Surg 2014; 260: 828-9.

7. Truant S, Pruvot F-R. Is there still a room to improve the safety of ALPPS procedure? A new technical note. Eur J Surg Oncol 2015; 41: 1554-5.

8. de Santibanes E, Alvarez FA, Ardiles V, Pekolj J, de Santibanes $M$. Inverting the ALPPS paradigm by minimizing first stage impact: the Mini-ALPPS technique. Langenbecks Arch Surg 2016; 401: 557-63.

9. de Graaf W, van Lienden KP, Dinant S, Roelofs JJ, Busch OR, Gouma DJ, Bennink RJ, et al. Assessment of future remnant liver function using hepatobiliary scintigraphy in patients undergoing major liver resection. J Gastrointest Surg 2010; 14: 369-78.

10. Levi Sandri GB, Vennarecci G, Ettorre GM. ALPPS in Setting Minimally Invasive Surgery for Hepatocellular Carcinoma. Ann Surg 2017; 266: e66-7.

\section{Correspondence and reprint request:} Stéphanie Truant, M.D.

Service de Chirurgie Digestive et Transplantation Hôpital HURIEZ, Rue M. Polonovski

$\mathrm{CHU}$, Univ Nord de France, F-59000 Lille, France

Tel.: +33 320 444260. Fax: +33 320446364 E-mail: stephanie.truant@ @chru-lille.fr 